\title{
The effect of the solvent nature on the quinoline derivatives physicochemical characteristics
}

\author{
C Vladimir V. Shcherbakov, ${ }^{1}$ Svetlana V. Kurbatova,,${ }^{1}{ }^{+}$and Margarita N. Zemtsova ${ }^{2}$ \\ ${ }^{1}$ Department of Physical Chemistry and Chromatography. Samara National Research University. \\ Acad.Pavlova St., 1. Samara, 443011.Russia.Fax:+7 (846) 334-54-17.E-mail: curbatsv@gmail.com \\ ${ }^{2}$ Samara State Technical University. Kuibyshev St., 153. Samara, 443010. Russia.
}

Keywords: quinoline derivatives, aqueous organic solutions, solvation energy, dipole moment, polar surface area of molecules, dependence of properties on the nature of the solvent.

\begin{abstract}
The influence of the solvent nature on some physicochemical parameters of the quinoline derivatives molecules is investigated. It was noted that a variety of intermolecular interactions arising between the dissolved substance and the solvent and often accompanied by the phenomena of solvation, association, etc. leads to a variety of structural and energy changes in such systems and complicating their description. The most urgent problems of solutions include issues related to the solubility and bioavailability of biologically active compounds and drugs, the study of their ability to dissolve, the permeability of biological barriers, targeted delivery, etc., as well as the problems associated with the study of sorption of organic compounds from aqueous-organic eluents, for example, in liquid chromatography.

Derivatives of quinoline (4-carboxy- and 4-aminoquinoline), known as potential drugs with various types of pharmacological action, were used as research objects. Using quantum chemical calculations, the dipole moment of the amino and carboxy derivatives of quinoline was determined, and the data obtained for vacuum and in solvents of various chemical nature were compared. A significant effect of solvent polarity on the dipole moment of quinoline derivatives dissolved in these solvents was found. The values of the solvation energy of quinoline derivatives in solvents of various chemical nature are calculated. It is shown that a change in the solvation energy is determined both by the structure of the molecules of the quinoline derivatives and by the polarity of the solvent. A nonlinear change in the energy of solvation with a change in the polarity of the solvent is established. A comparison is made of the values of the quinoline derivatives molecules polar surface area in solvents of various chemical nature. It was found that the polar surface area of the studied compounds changes slightly with a change in the nature of the solvent.
\end{abstract}

\section{References}

[1] Yu.Ya. Fialkov. Solvent as a means of controlling a chemical process. Leningrad: Chemistry. 1990. 240p. (russian)

[2] B.B. Damaskin., O.A. Petri., G.A. Tsirlina. Electrochemistry. Moscow: Chemistry, KolosS. 2006. 672p. (russian)

[3] V.P. Belousov, M.Yu. Panov. Thermodynamics of aqueous solutions of non-electrolytes. Leningrad: Chemistry. 1983. 264p. (russian)

[4] A.Yu. Tsivadze. Structural self-organization in solutions and at the phase boundary. Moscow: LCI. 2008. 554p. (russian)

[5] D.P. Elder, R. Holm, H. Lopez de Diego. Int. J. Pharm. 2013. Vol.453. No.1. P.88-100.

[6] C. Horváth, W. Melander, I. Molnár. J. Chromatogr. A. 1976. Vol.125. No.1. P.129-156.

[7] V.D. Shatz, O.V. Sahartova. High performance liquid chromatography. Riga: Zinatne. 1988. 390p.

[8] J. Joel, K. Mill. Chemistry of heterocyclic compounds. Moscow: Mir. 2004. 728p. (russian)

[9] N.A. Nekrasova, A.S. Savchenkova, N.Yu. Shumskaya, S.V. Kurbatova, and M.N. Zemtsova. Wateracetonitryle solutions features of 1,2,3,4-tetrahydroquinoline derivatives. Butlerov Communications. 2017. Vol.49. No.1. P.76-83. ROI: jbc-02/17-49-1-76

[10] O.A. Osipov, V.I. Minkin, A.D. Garnovsky. Handbook of dipole moments. Moscow: High school. 1971. 414p. (russian)

[11] N.A. Smirnova. Molecular theory of solutions. Leningrad: Chemistry. 1987. 336p. (russian)

[12] R.K. Lindsey, J.L. Rafferty, B.L. Eggimann, et al. J. Chromatogr. A. 2013. Vol.1287. P.60-82.

Kazan. The Republic of Tatarstan. Russia.

(C) Butlerov Communications. 2019. Vol.60. No.11. 
[13] Jacopo Tomasi, Benedetta Mennucci, Roberto Cammi. Chem. Rev. 2005. Vol.105. P.2999-3093.

[14] L. Pauling, P. Pauling. Chemistry. Moscow: Mir. 1978. 686p. (russian)

[15] O.A. Raevsky, S.V. Trepalin, V.Yu. Grigoryev et al. Khim.-pharm. Journ. 2014. Vol.48. No.1. P.30-32. (russian) 